\title{
The effects of increased acetylcholine levels during feeding on subsequent acquisition and extinction of barpressing*
}

\author{
HOWARD I. GLAZER \\ The Rockefeller Liniversity, . New York. New York 10021
}

\begin{abstract}
This study was designed to determine the effects of increased acetylcholine levels during daily feeding on extinction performance of a subsequently learned instrumental response. Two groups of Ss were employed, one receiving physostigmine injections prior to home cage feeding and the other receiving placebo injections. All Ss were then trained on a discrete-trial FR 10 schedule of reinforcement followed by extinction. The results indicated that the drug-injected group showed greater resistance to extinction of the subsequently learned barpress response. These data were interpreted as supporting the hippocampal theta-frustration hypothesis (Glazer, 1972).
\end{abstract}

It has recently been demonstrated by Gray (1970) that certain relationships exist between hippocampal electrical activity during the learning and extinction of an appetitively motivated response and resistance to extinction of that response. He has shown, for example, that induction of hippocampal theta rhythm within the context of rewarded instrumental responding tends to increase the persistence of that response during a subsequent extinction test, while increasing the occurrence of hippocampal theta during the extinction phase tends to accelerate extinction. As Gray points out, the operation of this mechanism in acquisition and extinction is a good physiological analog to the operation of frustrative nonreward in acquisition and extinction (Amsel, 1962). Gray also points out that this same increased occurrence of hippocampal theta occurs in response to novel environmental stimuli, which is in line with Amsel's more general statements about persistence (Amsel, 1972), which relate persistence to behavioral habituation.

In Gray's experiments, the increased hippocampal theta occurrence was produced by electrical stimulation of hippocampal pacemaker cells located in the medial septal nucleus (Shute \& Lewis, 1967). Stumpf (1965) has demonstrated that cholinergic stimulation of these hippocampal pacemaker cells also produces increased theta activity in the hippocampal formation and that this cholinergically induced hippocampal theta looks very much like that produced by the introduction of novel sensory stimulation.

It has also recently been demonstrated that pharmacological induction of hippocampal theta rhythm (employing physostigmine salicylate, a cholinesterase inhibitor) increases resistance to extinction if the drug is administered just prior to continuously rewarded

\footnotetext{
*The research herein reported was part of a dissertation submitted in partial fulfillment of the requirements of the $\mathrm{PhD}$ degree at the Lniversity of Texas at Austin. and was supported by National Science Foundation Grant GB-14990X to Abram Amsel. The author wishes to thank his $\mathrm{PhD}$ committee members. Abram Amsel. Clifford Morgan.- Devendra Singh. and James Swanson. for their assistance and support of this research.
}

acquisition trials, and decreases resistance to extinction if administered just prior to extinction trials (Glazer, 1972). This finding is supported by the work of Banks and Russell (1967), who, using the anticholinesterase compound OO-diethyl-S-ethyl-mercaptoethanol thiophosphate (Systox), found both increased extinction rates and improved sequential problem solving performance in rats, while Whitehouse (1966). employing the anticholinesterase physostigmine, has reported facilitation of performance in a black-white discrimination task resulting from faster response decrements to $\mathrm{S}-$. These findings all lend support to the hypothesis that hippocampal theta rhythm may be a physiological mechanism correlated with frustration.

In a recent extension of frustration theory (Amsel, 1972) to cover phenomena related to behavioral habituation, the question of the generality of persistence has been raised. In part, this question is: To what extent does persistence learned under one set of circumstances transfer to another set of circumstances? For example, from the work of Brown and Wagner (1964), showing fear-frustration transfer, and of Glazer and Amsel (1970), showing transfer between the consequences of nonreward and of goal blocking, it appears that there is some generality of persistence. Further evidence from a series of studies by Amsel, Glazer, Lakey, McCuller, and Wong (1973) indicates that a loud tone introduced either during instrumental responding or food consumption is also effective in producing persistence in a subsequent extinction test. All of these data indicate that persistence does generalize across the effects of different disruptive stimuli (e.g., from loud tones to conditioned frustration feedback stimuli, $s_{F}$ ) and across different responses (e.g., from goal approach to barpressing).

The persistence-modifying effects of physostigmine salicylate suggest that this drug can serve as a very useful tool in the further study of transfer of persistence. The question in this experiment is whether administration of this drug, temporally and spatially removed from the instrumental learning situation, could still affect persistence in that situation. Physostigmine injections 
were administered just before daily feeding in the home cage for several days. From the more general version of frustration theory (Amsel. 1972). it was predicted that the temporal contiguity of drug-induced theta rhythm in the hippocampus and food should provide the basis for the progress of counterconditioning which should result in persistence of a subsequently learned response.

\section{METHOD}

\section{Subjects}

Twenty naive male albino rats. ranging in age from 60 to 90 darys at the beginning of the experiment. were emploved. Ss were housed in individual sages and maintained under a 12-h light-dark syile.

\section{Apparatus}

The apparatus consisted of three identical operant conditioning chambers. measuring $22.5 \mathrm{~cm}$ long $\mathrm{x} 20 \mathrm{~cm}$ wide $\mathrm{x}$ $20 \mathrm{~cm}$ high. On the end panel of each chamber was mounted a Lehigh Valley retractable lever. $2.5 \mathrm{~cm}$ in from the left side and $5 \mathrm{~cm}$ above the floor. A Gerbrands feeder connected to the foodcup by a plastic tube was used to dispense reinforcement. Each chamber was housed in an individual sound-attenuating box equipped with a ventilation fan. Control of stimuli and recording of responses was done on-line with a digital PDP-8 I computer equipped with a SCAT system manufactured by Grason-Stadler.

\section{Procedure}

The Si were adjusted to a $10 \mathrm{~g} / 23$-h food-deprivation schedule for 1 week prior to injections. and were handled for 2 to $3 \mathrm{~min}$ daily during this period. Feeding. injections, and subsequent behavioral testing were carried out in the early afternoon hours. Ss were divided into two groups of 10 each. drug and control. For 12 days. Ss in the drug group received $.05 \mathrm{mg} / \mathrm{kg}$ of physostigmine salicylate [a dosage level previously shown to be effective in inducing hippocampal the ta rhythm (Glazer. 1972)]. while control Ss received an equal volume of physiological saline. Injections were administered intraperitoneally immediately before the Ss received their daily food rations. The order of injections was randomized over all Ss for each day as well as over days. Following the injection-feeding phase. all Ss were left untreated on the $10 \mathrm{~g}$ deprivation schedule for 3 days to control for possible carry-over effects of the drug into barpressing acquisition.

All Ss were first shaped to FR 10 responding. starting with FR 1 for 2 days. followed by FR 2 for 2 days. after which the ratio requirement was increased by 2 responses every other day until FR 10 was reached. There were four trials a day during shaping and for the remainder of the experiment. During shaping. acquisition. and extinction of the lever response. a discrete-trial procedure was employed. At the beginning of each trial. the bar was extended and remained available until the $S$ performed the required number of responses. Lpon completion of the FR requirement. a $300-\mathrm{mg}$ Noyes pellet was delivered. and the lever was retracted simultaneously. The duration of the intertrial interval (ITI) was 60 sec.

In both the drug and control conditions. Ss were maintained on the FR 10 schedule for 15 days, followed by 12 day extinction. In extinction. if an $S$ did not respond within $60 \mathrm{sec}$ of the lever extension, or if $60 \mathrm{sec}$ elapsed since the previous response, the bar was automatically retracted and the 60 -sec ITI was initiated.

\section{RESULTS AND DISCUSSION}

\section{Drug-Feeding Phase}

Observations of the Ss during the drug-feeding phase of the experiment confirmed results of a previous study. (Glazer. 1972) showing that physostigmine salicylate at the dosage level employed does not produce any observable motor deficits or aversive side effects. such as illness. In consideration of the hypothesized relationship between hippocampal theta rhythm and activity (Black et al. 1970: Vanderwolf. 1971). it is also worth noting that drug-injected Ss did not show any observable increases in activity. Finally. there was no evidence that the drug affected the rate at which the animals consumed their daily food ration. It should be pointed out that none of the above observations were quantified. and more rigorous investigations mav show measurable changes in these parameters resulting from physostigmine injections.

A comparison of the effects of electrical vs pharmacological induction of hippocampal theta on both appetitively conditioned instrumental responses and unconditioned consummatory responses brings to light some interesting differences. It was demonstrated in a previous experiment (Glazer. 1972) that drug-induced theta did not have any effect on the acquisition of an appetitively motivated barpress response. and in both the earlier experiment and the present one. there was no indication that drug-induced theta affected the consummatory response (eating). Electrical induction of hippocampal theta, on the other hand. significantly suppresses an appetitively motivated barpress response (Glazer, in press) or locomotor response (Gray. 1972). but does not affect consummatory responses (Gray. 1970).

This apparent incongruity fits in with the hippocampal theta-frustration hypothesis of Glazer (1972). According to this point of view. hippocampal theta rhythm is a correlate of conditioned or anticipatory states (based on aversive LCSs). and so it is ' not surprising that induction of hippocampal theta rhythm (electrically or pharmacologically) does not affect unconditioned consummatory responses. Although the data does not permit any definitive conclusions on the question of why electrically. but not pharmacologically. induced hippocampal theta disrupts appetitively motivated instrumental responding. a tentative hypothesis can be offered.

One possible explanation for this difference is that the electrically induced hippocampal theta rhythm has a rapid onset and a brief duration (usually about $5 \mathrm{sec}$ medial septal stimulation is used), while pharmacologically induced hippocampal theta has a slower onset (about $5 \mathrm{~min}$ using $.05 \mathrm{mg} / \mathrm{kg}$ physostigmine salicylate injected intraperitoneally') and a longer duration (about $15 \mathrm{~min}$ ). 
Fig. 1. Acquisition and extinction of FR 10 lever responding showing both groups over the three response measures.

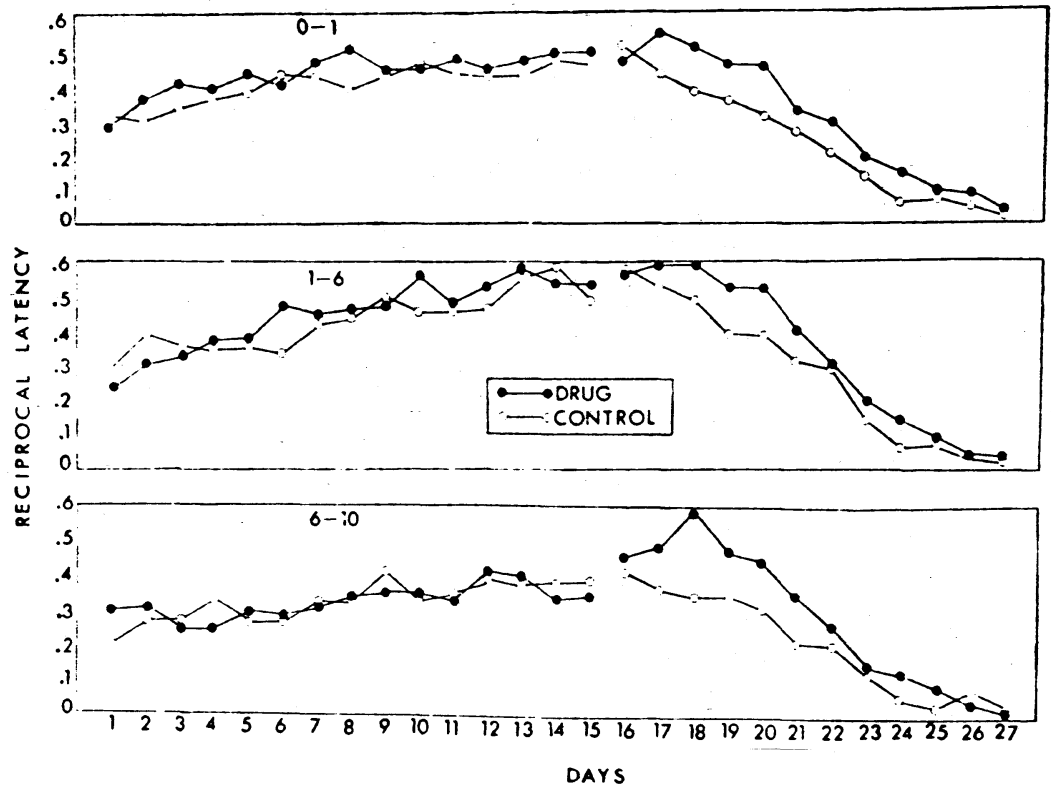

\section{Barpress Acquisition and Extinction}

On each trial, time to complete the FR 10 sequence was divided into three measures: (1) response time from the lever extension to the $1 \mathrm{st}$ press. (2) time from the 1 st to the 6th press, and (3) time from the 6th to the 10 th press. An analysis of variance was done on the reciprocal time data (response rate) for each measure. Figure 1 shows the results for both groups over acquisition and extinction of FR 10 responding. All Ss showed acquisition of the FR 10 responding as characterized by an increased rate of responding over days in all three measures ( $F s=5.58,7.33$, and 3.53, df $=14.252 . \mathrm{p}<.01)$. There were no significant main effects or interactions involving the group variable in any measure. The relatively flat acquisition curves that appear in Fig. 1 resulted from the slow shaping procedure used.

During extinction. both groups showed a decline in responding over days in all three measures $(F s=50.02$, 29.95. and 37.22, $\mathrm{df}=11.198 . \mathrm{p}<.01$ ). Measures 2 and 3 also showed declining response rates over trials within days $(F s=5.47$ and 3.00. $\mathrm{df}=3.54, \mathrm{p}<.01$ ) as well as differential group extinction rates over days (i.e., Group by Day interaction. Fs $=2.00$ and 1.88 , df $=11.198$. $\mathrm{p}<.05$ ). Finally. Measure 3 yielded a significant Days by Trials Within Days interaction $(\mathrm{F}=1.56 . \mathrm{df}=33.594$. $\mathrm{p}<.05)$. indicating greater response decrements over trials within days for both groups as extinction progressed.

The significant difference in extinction rates of the two groups in the second and third response measures points to the effectiveness of the drug-feeding sequence in producing response persistence in a new situation. Since the hippocampal theta-inducing drug was never introduced into the instrumental training or extinction situation. the present finding cannot be accounted for on the basis of any primary drug-induced state. Carry-over effects of nonassociative drug-induced factors, such as changes in motivational level, also seem unlikely, since there was no evidence that the drug modified consummatory behavior or activity level. As stated earlier, however, changes in nonassociative factors cannot be completely ruled out. It is possible, for example, that repeated injections of physostigmine may have produced long-lasting changes in the sensitivity of cholinergic receptors. An associative interpretation of the present data seems to be in order. Since no motor or motivational changes were observed under the drug, it is not likely that increased hunger or activity levels were conditioned in the drug-feeding phase of the experiment. The findings do show that persistence transferred across responses (food approach and consumption to barpress), external stimuli (home cage to Skinner box), and internal disruptive stimuli (physostigmine-produced stimuli to frustration-produced stimuli). A number of investigations are presently being conducted in an attempt to localize the mechanisms and pathways involved in the drug effect and to better substantiate the hippocampal theta-frustration hypothesis. This present finding is taken. however, as preliminary support for both the more general theory of persistence of Amsel (1972) and the identification of hippocampal theta rhythm with frustrative effects suggested by Gray (1970) and Glazer (1972).

\section{REFERENCES}

Amsel, A. Frustrative nonreward in partial reinforcement and discrimination learning: Some recent history and a theoretical extension. Psychological Review, 1962, 69, 306-328.

Amsel, A. Behavioral habituation, counterconditioning, and a general theory of persistence. In A. H. Black and W. F. Prokasy (Eds.). Classical conditioning: II. New York: Appleton-Century-C rofts. 1972. 
Amsel. A.. Glazer. H.. Lakey. J. R.. McCuller, T. G.. \& Wong. P. $T$. P. Introduction of acoustic stimulation during acquisition and resistance to extinction in the normal and hippocampally damaged rat. Journal of Comparative \& Physiological Psychology . 1973. 84. 176-186.

Banks. A.. \& Russell. R. W. Effects of chronic reduction in acetylcholinesterase activity on serial problem solving behavior. Journal of Comparative \& Physiological Psychology. 1967. 64. 262-267.

Black. A. H.. Young. G. A..\& Batenchuck. C. Aroidance training of hippocampal theta rhythm in Flaxedilized dogs and its relation to skeletal movement. Journal of Comparative \& Phỵsiological Psychology, 1970. 77. 465-480.

Brown. R. T.. \& Wagner. A. R. Resistance to punishment and extinction following training with shock or nonreinforcement. Journal of Experimental Psychology, 1964. 68. 503-507.

Glazer. H. I. Physostigmine and resistance to extinction. Psychopharmacologia, 1972, 26. 387-394.

Glazer, H. Instrumental response persistence following the induction of hippocampal theta frequency during fixed-ratio responding. Journal of Comparative \& Physiological Psychology, 1973, in press.

Glazer. H., \& Amsel, A. Transfer of persistence effects from frustration produced by blocking to frustration produced by nonreinforcement. Psychonomic Science, 1970, 18, 311-312.
Gray, J. A. Sodium amobarbitol, the hippocampal theta rhythm, and the partial reinforcement extinction effect. Psychological Review. 1970. 77. 465-480.

Gray. J. A. Effects of septal driving of the hippocampal theta rhythm on resistance to extinction. Physiology \& Behavior. 1972. 8. 481-490.

Shute. C. C. D.. \& Lewis. P. T. The ascending cholinergic reticular system: Neocortical. olfactory. and subcortical projections. Brain. 1967. 90. 497-520.

Stumpf. C. Drug action on the electrical activity of the hippocampus. International Journal of Neurobiology, 1965. 14. 77-138.

Vanderwolf, C. H. Limbic-diencephalic mechanisms of voluntary movement. Psychological Review. 1971, 78, 83-113.

Whitehouse. J. II. The effects of physostigmine on discrimination learning. Psychopharmacologia. 1966. 9. 183-188.

(Received for publication . Iarch 15. 1973: revision received July 26,1973 .) 